\title{
EFFECT OF DIFFERENT NOZZLES ON THE PERFORMANCE OF PULSE DETONATION ENGINE- A REVIEW
}

\author{
T.K. Jindal \\ Associate Professor, Aerospace Engineering Department, PEC University of Technology Chandigarh \\ tkjindal@yahoo.com
}

\begin{abstract}
Pulse Detonation Engine (PDE) has recently got fancy of aero-propulsion community due to its simplicity and advantages over current propulsion systems. The PDE operates on the detonation of combustion products, which is produced by burning of a reactive gas mixture at normal pressure and temperature. The reactants are then at a high pressure and high temperature. The impulsive thrust is produced through rapid ignition and formation of detonation waves. The present paper is a review of various efforts made to enhance the Pulse detonation Engine performance by using different types of nozzle geometries.
\end{abstract}

Keywords: Pulse Detonation, Nozzle, Thrust Augmentation, Rotating Wave.

\section{INTRODUCTION}

The Pulse detonation Engine (PDE) has become very popular recently due to its performance and design advantages over conventional propulsive systems[1-10]. The PDE uses detonation waves that are initiated at the end of a combustor and propagate through a propellant mixture with a very high supersonic speed and produce very high pressure and temperature. The initiated combustion either detonates with high energy spark or transitioned from deflagration to detonation with the help of turbulizers. Due to the rapid detonation process, nearly constant volume combustion is achieved, which has a higher thermal efficiency than a traditional constant pressure combustion process. The fig-1 gives the comparison of the Brayton and Humphrey cycle. Humphrey cycle has almost double the area under the curve giving Pulse detonation a higher work done efficiency.

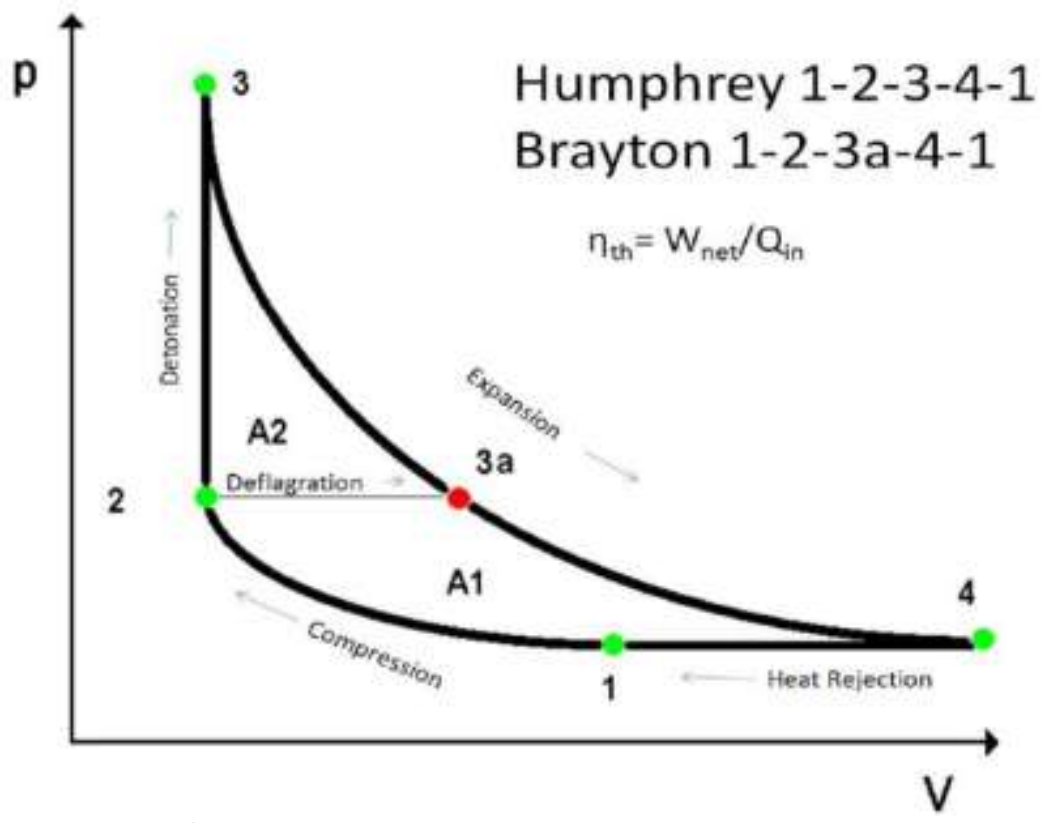

Fig.-1 Comparison of Brayton and Humphrey cycle.

The Pulse Detonation Engine is an unsteady propulsion device. It is based on the detonation mode of combustion, which involves the burning of a reactive gas mixture at the high pressure and high temperature behind a propagating shock wave. The high pressure combustion products, acting on the thrust plate at the front end of the engine, produce the forward thrust.
The use of nozzles to improve the performance of conventional steady propulsion system has been tried and tested by many researchers.In this paper an effort has been made to investigate the effects of nozzle geometry on the performance of PDE. 


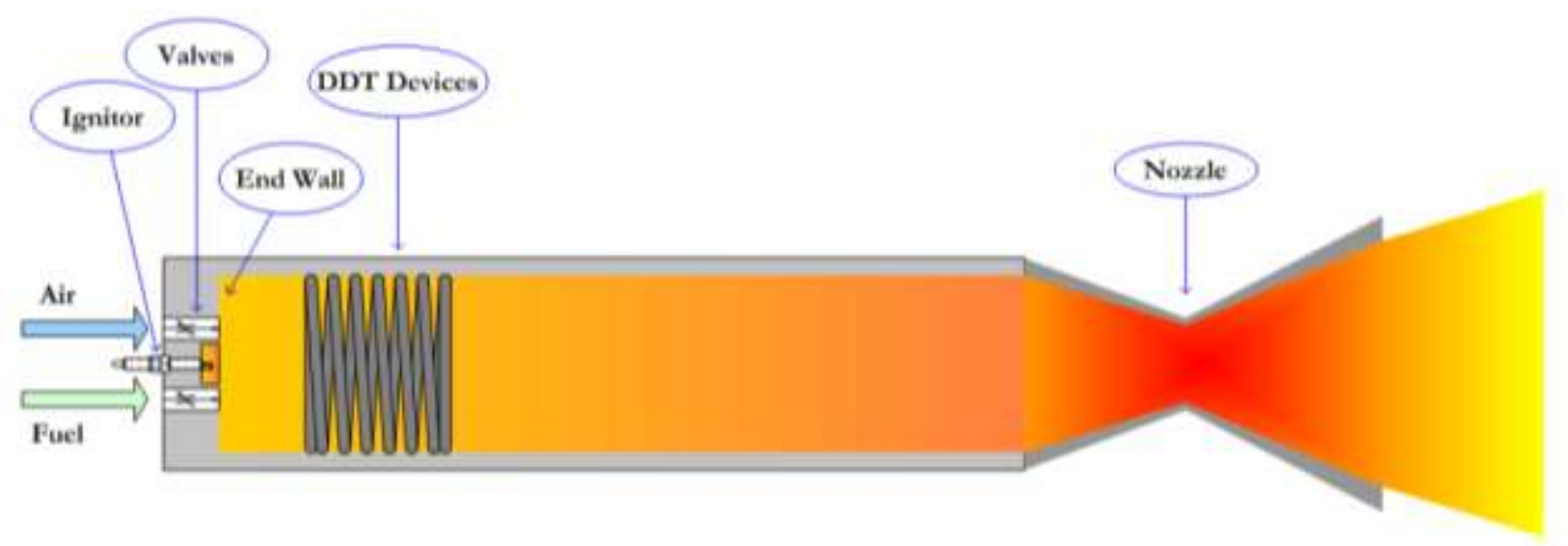

Fig - 2 PDE with nozzle

\section{REVIEW OF WORK CARRIED OUT}

Chen Wenjuanet.al. [15] investigated experimentally the effect of nozzles on thrust and inlet pressure of an airbreathing Pulse Detonation Engine (APDE). The experiments were carried out on an APDE of diameter 68 $\mathrm{mm}$ and length $2050 \mathrm{~mm}$, using gasoline/air mixture. The nozzles used in the test were straight nozzle, converging nozzle, converging-diverging nozzle and diverging nozzle. It was found that the thrust augmentation was better in case of converging-diverging nozzle, diverging nozzle and straight nozzle as compared to converging nozzle.

Diverging nozzle having large exit section and convergentdiverging nozzle having large throat section produced the largest thrust augmentation at all frequencies ranging from $20 \%$ to $40 \%$.

It was also found that the filling pressure and average peak pressures at inlet are higher in case of converging-diverging nozzles and diverging nozzles having large throat section than that of straight and converging nozzles at different frequencies.

Yu. Yan et.al.[14] made experimental investigations on the effect of bell shaped nozzles on the performance of Pulse Detonation Rocket Engine (PDRE). The study was done on PDRE using different configurations of convergent divergent nozzles. The fuel and oxidizer used were liquid kerosene and gaseous oxygen respectively and nitrogen was used as purge gas. The maximum thrust augmentation was produced by the nozzle with 5.325 contraction area ratio and expansion area ratio of 12 . This augmentation is nearly $21 \%$. These nozzles are found to be beneficial for PDRE for the fill-fraction range of 0.29 to 0.37 . The effect of cycle frequency on nozzle performance was not found to besignificant.

Shao Yetao et al[13] investigated the continuous detonation engine (CDE) and effect of different types of nozzles on its propulsion performance. The investigation was done using three-dimensional numerical simulation. A one step chemical reaction model was used. Monotonicity-preserving weighted essentially non-oscillatory (MPWENO) scheme was used to solve flux terms. The types of nozzles used to investigate the performance of $\mathrm{CDE}$ are constant-area nozzle, Laval nozzle, diverging nozzle and converging nozzle. It was found that Laval nozzle has better results as compared to other three nozzles; it produced the best performance of $1800 \mathrm{~N}$ thrust, gross specific impulse of $1750 \mathrm{~s}$ and mass rate of $313 \mathrm{~kg} /\left(\mathrm{m}^{2} . \mathrm{s}\right)$.

W.S. Stuessy et al [16] investigated experimentally the effect of nozzle geometry on the performance of a pulse detonation wave engine. The tests were conducted on two chamber geometries, cylindrical and annular with and without exhaust nozzles. The nozzles used in the testes were conical divergent nozzles with angle of divergence of 9.52 and 14.24. the fuel and oxidizer used are propane and oxygen respectively. With stoichiometric ration of fuel and oxidizer and at a frequency of 20.4 to 28.5 , the performance achieved

by annular configuration with 14.24 degree nozzle was found maximum.

M. Arian et al [12]numerically investigated the effect of nozzle angle and length on the frequency and impulse of the pulse detonation engine from viewpoint of gas dynamics. The quasi one dimensional code was used to solve the equations used.

After investigating the effect of presence of nozzle in the engine in general, the effect of nozzle geometry was studied numerically. For this it was assumed that the total length of the engine was $1 \mathrm{~m}$, the product temperature $2500 \mathrm{~K}$, product pressure variation from 10 to 20 bar and following four nozzle geometries were studied.

1. $0.9 \mathrm{~m}$ of tube length and $0.1 \mathrm{~m}$ of nozzle length with divergent angle of $0,5,7,10$ degrees.

2. $0.8 \mathrm{~m}$ of tube length and $0.2 \mathrm{~m}$ of nozzle length with divergent angle of $0,5,7,10$ degrees.

3. $0.7 \mathrm{~m}$ of tube length and $0.3 \mathrm{~m}$ of nozzle length with divergent angle of $0,5,7,10$ degrees.

4. $0.6 \mathrm{~m}$ of tube length and $0.4 \mathrm{~m}$ of nozzle length with divergent angle of $0,5,7,10$ degrees.

The results show that the direct nozzle improves the impulse as compared to diverging nozzle but on the other hand a diverging nozzle increases the cycle frequency in 
comparison with the direct nozzle. Both direct nozzle with acceptable maximum length and diverging nozzle of small length and high divergence angle improve the thrust of the engine.

M. Ruhul Amin et al[11] made numerical investigations on the effects of nozzle geometry on the performance of a Pulse Detonation Engine, using Computational Fluid Dynamics (CFD) software. The various nozzle geometries and operating conditions were considered in the simulation. The results indicated that the optimum performance of the engine was achieved by expanding nozzle for optimum value of the exit area of the nozzle.

C.I. Morris[17] did numerical modeling of Pulse Detonation Rocket Engine gasdynamics and performanceusing four different engine geometries i.e. a baseline detonation tube, the tube with extension, and the tube with two types of converging-diverging (C-D) nozzles. The effects of the convergent-divergent nozzles was found to be more significant than the straight extension in improving the engine performance at high pressure ratios.

Hasan ZakariaRouf[18] performed numerical simulation on parametric study on performance optimization of Pulse Detonation Engine (PDE). In this study it was observed that the use of nozzle in PDE significantly improves the performance of PDE. The divergent nozzle improves the impulse generation rate and if straight nozzle is used it gives slower impulse generation so do convergent divergent nozzle. Nozzle geometry also affect the cycle time. At very high altitudes where the ambient pressure is very low, the nozzle helps to increase the specific impulse of PDE. It was concluded by the results that for PDE performance optimization, a nozzle with variable geometry are best suitable.

Tae-Hyeong Yi et al (19) studied the effect of nozzle geometry i.e., shape, length and angle on the performance of continuously rotating detonation engine with the help of numerical simulation. The performance parameters of thrust and specific impulse were observed with use of four different types of nozzles, to find out the best suitable geometry of the nozzle. The engine with divergent nozzle having divergent angle of 10 and length $0.04 \mathrm{~m}$ gave the best performance and minimum total pressure loss as compared to other nozzles.

\section{CONCLUSION}

From the above reviewed work it can be noted that the effect of nozzle geometry helps enhance the performance of a Pulse Detonation engine. In case of air breathing pulse detonation engine a divergent nozzle with large expansion ratio or a convergent-divergent nozzle with large throat area enhances the engine thrust from $20 \%$ to $40 \%$. It was also found that the nozzle increases the cycle impulse and the cycle frequency. Observations are also made that a divergent nozzle is more effective than a converging-diverging nozzle at low ambient pressure.
The nozzle, hence, is instrumental in enhancement of performance of a PDE in terms of thrust augmentation, increase in specific impulse and increase in cycle frequency.

\section{REFERENCES}

[1]. Kailasanath, K. "Recent Developments in the Research on Pulse Detonation Engines," AIAA Paper 20020470, AIAA 40th Aerospace Sciences Meeting, Reno, NV, 14-17 Jan. 2002.

[2]. E. D. Lynch and R. B. Edelmant "Analysis of the Pulse Detonation Wave Engine Developments In HighSpeed Vehicle Propulsion Systems", Progress in Aeronautics and Astronautics, 1996, pp. 473-51.

[3]. E. Schultz, E. Wintenberger, J. Shepherd, "Investigation of Deflagration to Detonation Transition for Application to PulseDetonation Engine Ignition Systems", a report, California Institute of Technology, Pasadena, CA 91125 USA

[4]. J. E. Shepherd, J. Austin, T. Chao, E. Schultz, E. Wintenberger, S. Jackson, M. Cooper, "Detonation Initiation, Diffraction, and Impulse" a report, Graduate Aeronautical Laboratories, California Institute of TechnologyPasadena, CA 91125 USA

[5]. T. K. Jindal, Pulse detonation engine - A next gen propulsion, International Journal of Modern Engineering Research (IJMER) www.ijmer.com Vol.2, Issue.6, Nov-Dec. 2012 pp-4083-4085 ISSN: 22496645.

[6]. T. K. Jindal, Stress Analysis of Pulse Detonation Engine Tube, International Journal of Modern Engineering Research (IJMER) www.ijmer.com Vol.2, Issue.6, Nov-Dec. 2012 pp-4080-4082 ISSN: 22496645

[7]. Subhash Chander, TK Jindal, Integration Challenges in Design and Development of Pulse Detonation Test Rig, ISSN: 2278 - 8875, International Journal of Advanced Research in Electrical, Electronics and Instrumentation Engineering, Vol. 1, Issue 4, October 2012.

[8]. D. Mahaboob Valli, T.K. Jindal, "Thrust Measurement of Single Tube Valve less Pulse Detonation Engine, International Journal of Scientific \& Engineering Research Volume 4, Issue3, March-2013 ISSN 22295518.

[9]. D. Mahaboob Valli, T.K. Jindal, Application of Taguchi Method for Optimization of Physical Parameters Affecting the Performance of Pulse Detonation Engine;. Journal of Basic and Applied Engineering Research, Print ISSN: 2350-0077; Online ISSN: 2350-0255; Volume 1, Number 1; September, 2014 pp. 18-23 @ KrishiSanskriti Publications.

[10].Subhash Chander, TK Jindal, A study of possible technical aspects needed to be addressed in respect of system engineering of surface to air missile by application of pulse detonation engine, IJME, Volume 1, Spl. Issue 1 (2014) e-ISSN: 1694-2302 | p-ISSN: 1694-2418.

[11].M. Ruhul Amin, Hasan Z. Rouf, Jean-Luc Cambier, "Numerical Investigation on the Effect of Nozzle Geometry on the Performance of Pulse Detonation 
Engine", Journal of Mechanical Engineering, Vol-51, pg. 484-490, 2005.

[12].M. Arian, A. M. Tahsini, "Nozzle Effects on Pulse Detonation Engines Performance",European Conference on Computational Fluid Dynamics, 2006.

[13].Shao Yetao, Liu Meng, Wang Jianping , "Continuous Detonation Engine and Effects of Different Types of Nozzle on its Propulsion Performance", Chinese Journal of Aeronautics, Vol.23, pg. 647-652, 2010.

[14].Yu. Yan, W. Fan,K. Wang, Ya. Mu, “ Experimental Investigation of the Effect of Bell-Shaped Nozzles on the Two-Phase Pulse Detonation Rocket Engine Performance", Journal of Combustion, Explosion and Shock waves, Vol. 47, pg. 335-342, 2011.

[15].Chen Wenjuan, Fan Wei, Zhang Qun, Peng Changxin, Yuan Cheng, Yan Chuanjun, "Experimental Investigation of Nozzle Effects on Thrust and Inlet Pressure of an Air-Breathing Pulse Detonation Engine", Chinese Journal of Aeronautics, Vol.25, pg. 381-387, 2012.

[16].W.S. Stuessy, W.R. Wilson, "Influence of Nozzle Geometry on the Performance of a Pulse Detonation Wave Engine", American Institute of Aeronautics and Astronautics, AIAA97-2745, 1997.

[17].C.I. Morris, "Numerical Modeling of Pulse Detonation Rocket Engine Gasdynamics and Performance", Journal of Propulsion and Power, Jan 2004.

[18].Hasan ZakariaRouf, "Parametric study for performance optimization of pulse detonation engines", M.S. thesis, Montana State University, Bozeman, MT, 2003.

[19].Tae-Hyeong Yi et al, "Effect of nozzle shapes on the performance of continuously rotating detonation engine", $48^{\text {th }}$ AIAA Aerospace, Florida, 2010. 